\title{
REPORT ON THE 2007 INTERNATIONAL WORKSHOP ON HUMAN PAPILLOMAVIRUSES AND CONSENSUS RECOMMENDATIONS FOR CERVICAL CANCER PREVENTION
}

\author{
Magdalena Grce ${ }^{1,2}$, Philip Davies ${ }^{2}$, Marc Arbyn ${ }^{3}$, Ahti Anttila ${ }^{4}$, Goran Grubišićs ${ }^{5}$ Ika Kardum-Skelin 6 , \\ Amanda Herbert ${ }^{7}$, Joseph Jordan ${ }^{8}$, Lawrence von $\mathrm{Karsa}^{9}$ \\ 'Division of Molecular Medicine, "Ruđer Bošković" Institute, Department of Molecular Medicine, Zagreb, Croatia \\ ${ }^{2}$ European Cervical Cancer Association, Central Office, Lyon, France \\ ${ }^{3}$ Scientific Institute of Public Health, Unit of Cancer Epidemiology, Brussels, Belgium \\ ${ }^{4}$ Mass Screening Registry, Finnish Cancer Registry, Helsinki, Finland \\ EUniversity Hospital "Sisters of Charity", Clinic of Obstetrics and Gynaecology, Zagreb, Croatia \\ ${ }^{6}$ University Hospital "Merkur", Internal Medicine Clinic, Zagreb, Croatia \\ 'Histopathology Department, Guy's \& St Thomas' NHS Foundation Trust, London, UK \\ ${ }^{8}$ Birmingham Hospital for Women, Department of Obstetrics and Gyneacology, Birmingham, UK \\ IInternational Agency for Research on Cancer, European Cancer Network, Lyon, France
}

\section{SUMMARY}

National and international experts in cervical cancer prevention met at the International Workshop on Human Papillomaviruses and Consensus Recommendations for Cervical Cancer Prevention to review the current evidence and assess the potential for improvement in cervical cancer prevention and to develop plans for implementation of cervical cancer prevention programmes in Croatia. Key recommendations were developed and adopted during the course of the meeting. The process of bringing national experts together with internationally recognized experts in an open forum for the development of consensus recommendations could serve as a model for other countries seeking to implement or improve cervical cancer prevention programmes.

Key words: cervical cancer, prevention, screening, HPV vaccination, Southeast Europe, Croatia

Address for correspondence: M. Grce, Ruđer Bošković Institute, Department of Molecular Medicine, Bijenička 54, Zagreb, Croatia. E-mail: grce@irb.hr

\section{INTRODUCTION}

Elucidation of the causal role of oncogenic Human papillomavirus (HPV) types in cervical cancer (1) has led to rapid advances in HPV testing and vaccination in recent years with the prospect of further improvements in cervical cancer prevention.

Aproximately 9,000 women develop cervical cancer and about 4,600 die from the disease each year in Southeast Europe (Albania, Bosnia \& Herzegovina, Bulgaria, Croatia, Cyprus, Greece, Former Yugoslavian Republic of Macedonia, Moldova, Romania, Serbia \& Montenegro and Slovenia) (2, 3). In most of these countries; opportunistic cervical cancer screening has been practiced for decades although cancer rates show that the effect of these approaches is limited, while the burden of disease could still be substantially reduced by implementation of organised, population-based screening programmes.
Croatia initiated opportunistic screening in 1953 and subsequently saw cervical cancer incidence rates drop from 26 to $14 / 100,000$ women-years $(4,5)$. However, incidence rates have remained stable for the past 15 years and the country is now seeking to establish an organised, population-based screening programme to achieve further reductions in this disease. In order to ensure the optimal efficacy of this programme, an international workshop on HPV and cervical cancer prevention was held from 18 to 21 April, 2007, in Cavtat, Croatia, to review the current evidence and develop consensus recommendations on cervical cancer screening and HPV vaccination. An international colposcopy training course held under the auspices of the European Federation for Colposcopy was held a day after the workshop.

The workshop was organised by the Ruđer Bošković Institute, the Croatian Society for Colposcopy and Cervical Pathology of the Croatian Medical Association, the Croatian Society for Clini- 
cal Cytology of the Croatian Medical Association, the European Cervical Cancer Association, and the International Papillomavirus Society and was held under the auspices of the Ministry of Health and Social Welfare of the Republic of Croatia, the Ministry of Science, Education and Sports of the Republic of Croatia, the European Federation for Colposcopy and Mrs Jadranka Kosor, Vice Prime Minister and Minister of Family and Veterans' Affairs and Intergenerational Solidarity.

Over 130 cytologists, epidemiologists, gynecologists, pathologists, virologists, and screening and prevention experts from 20 countries and the International Agency for Research on Cancer attended the conference and discussed the current state of knowledge and future prospects for cervical cancer control. Plans for implementation of cervical cancer screening in Croatia were also reviewed. The attending national and international experts agreed on the following conclusions and key recommendations for programme implementation in Croatia.

\section{KEY CONCLUSIONSAND RECOMMENDATIONS FOR CERVICAL CANCER PREVENTION IN CROATIA}

\section{Cervical Cancer Screening}

Over $80 \%$ of cervical cancer cases and deaths can be prevented by effective, organised screening programmes (6).

The burden of cervical cancer in Croatia, although lower than in some new EU member states and applicant countries, is still a significant public health problem $(2,7,8)$.

Despite considerable expertise and available resources for cytology-based screening (8), Croatia has yet to implement an organised screening programme aiming for further reduction of the burden of cervical cancer, as recommended by the Council of the European Union in 2003 (9) and the European Guidelines for Quality Assurance in Cervical Cancer Screening (10).

Plans for the implementation of an organised screening programme have been prepared by the members of the 2003 Working Group of the Croatian Ministry of Health and Social Welfare (4, $8,11)$. A summary of recommendations for Croatia was prepared by the members of the 2003 Working Group and presented at the current meeting. The participants of the International Workshop on HPV and Consensus Recommendations for Cervical Cancer Prevention endorse and support the proposal of the 2003 Croatian Working Group to implement an organised cervical cancer screening programme.

Implementation of the screening programme should begin with population-based pilot projects in which the adequacy of all programme elements, including quality assurance, is successfully demonstrated. This will permit timely and appropriate modifications during the rollout phase.

Prior to sending initial invitations, and prior to expansion of successfully piloted activities to other parts of the country, the responsible authorities are advised to consult internationally recognized experts in cervical cancer screening to ensure that the following key points have sufficiently been taken into account:

- Uniform national screening policy (targeted age groups, eligibility, screening test and interval) based on population-based screening

- Mechanisms to discourage unorganized screening due to its inherent limitations with respect to quality assurance (QA) and cost-effectiveness.

- Financial plan and sufficient resources for all components of the screening programme, including the infrastructure for data collection and QA, and management of screen positives.

- Professional guidelines and legally binding, comprehensive QA regulations for organised screening fulfilling the standards and recommendations of the EU guidelines (9). Special provision should be made for: population-based invitation and evaluation; specialized training; uniform documentation and continuous monitoring and quality improvement based on a computerized information system covering the entire screening process; feedback to health professionals with the purpose to inform and educate; programme coordination; and certification.

- Framework for evaluation and monitoring based on complete cancer registration and linkage with screening data bases.

- Coordinating institution with overall responsibility for programme implementation and QA.

- Programme evaluation, including requisite organizational aspects.

- International collaboration and cooperation in QA and evaluation.

- Comprehensive information on the programme, adequately addressing the needs of the target population, the general public and the media, health professionals, stake-holders and decision-makers.

- Encouragement of high participation of women in screening and compliance to recommended management of screen-positives through appropriate, balanced, evidence-based information of the benefits and risks, which enables women to make an informed choice.

\section{HPV Vaccination}

The participants in the workshop also note that HPV vaccines have shown efficacy in prevention of cervical cancer precursors related to the HPV types included in the vaccine. This development is welcomed, because the vaccines have the potential to improve cervical cancer control through primary prevention. However, many aspects of immunization policy need to be clarified (12), and the greatest impediment to widespread implementation is the current excessive cost of the vaccine.

Although prophylactic vaccination is likely to provide important future health gains, cervical screening must be continued. HPV vaccination and screening are complementary preventive strategies. Neglecting screening in favour of vaccination has the potential to paradoxically lead to an in increase in the cervical cancer burden (13). Therefore, implementation of vaccination should not replace implementation of organised screening. If resources are limited, priority should currently be given to implementation of a population-based screening programme. Furthermore, if HPV vaccination is implemented it should only be offered through a population-based approach, with a population-based vaccination registry and other monitoring mechanisms that can be linked to the screening and cancer registries (14).

\section{Management of Abnormal Cervical Smears}

A group of experts attending the workshop developed additional consensus recommendations for the management of 
abnormal cytology and cervical intraepithelial neoplasia (CIN), which are on line with the European Guidelines for Quality Assurance in Cervical Cancer Screening (10).

\section{CONCLUSION}

The process of international cooperation and collaboration in reviewing the evidence and assessing the prospects for cervical cancer prevention in a multidisciplinary workshop was highly effective in reaching an expert consensus on recommendations for Croatia. This exercise could be useful for other countries preparing to implement or improve cervical cancer prevention programmes.

\section{Acknowledgements}

The authors are grateful to members (listed in alphabetical order) of (1) the Working Group of the Official Recommendation to the Croatian Ministry of Health and Social Welfare for the Prevention of Cervical Cancer in Croatia: Damir Babić (Zagreb, Croatia), Ante Čorušić (Zagreb, Croatia), Vesna Mahovlić (Zagreb University Hospital Center, Zagreb, Croatia), Marija Pajtler (Osijek, Croatia) and Ariana Znaor (Zagreb, Croatia), (2) the Working Groups on Consensus Recommendation for the Management of Abnormal Cytology and Cervical Intraepithelial Neoplasia (CIN): Vesna Kesić (Belgrade, Serbia), Walter Prendiville (Dublin, Ireland) and Charles Redman (Stoke-on-Trent, UK), (3) and the other invited speakers: Silvana Audy-Jurković (Zagreb, Croatia), Thomas R. Broker (Birmingham, USA), Francesca Carozzi (Florence, Italy), Silvia Franceschi (IARC), Mina Desai (London, UK), Anka Dorić (Zagreb, Croatia), Joakim Dillner (Malmo, Sweden), Lena Dillner (Malmo, Sweden), Blaženka Grahovac (Rijeka, Croatia), Ljubica Glavaš Obrovac (Osijek, Croatia), Lutz Gissman (Heidelberg, Germany), Herman Haller (Rijeka, Croatia), Ole Erik Iversen (Bergen, Norway), Dubravko Lepušić (Zagreb, Croatia), Ines Krivak Bolanča (Zagreb, Croatia), Vanja Kaliterna (Split, Croatia), Vlastimir Kukura (Zagreb, Croatia), Marina Kuzman (Zagreb, Croatia), Chris Meijer (Amsterdam, The Netherlands), Sonia Pagliusi (Geneva, Switzerland), Alenka Repše Fokter (Celje, Slovenia), Lukáš Rob (Prague, Czech Republic), Tomislav Rukavina (Rijeka, Croatia), Senka Sabolović Rudan (Zagreb, Croatia), Ruth Tachezy (Prague, Czech Republic), Danijela Vrdoljak Mozetič (Rijeka, Croatia), Marjolein van Ballegooijen (Rotterdam, The Netherlands) and Magnus von Knebel Doeberitz (Heidelberg, Germany) as well as to (4) all the participants of the International Workshop on Human Papillomavirus and Consensus Recommendations for Cervical Cancer Prevention coming from Croatia, Belgium, Bosnia and Herzegovina, Estonia, Former Yugoslav Republic of Macedonia, Portugal, Romania, Slovenia, Serbia, UK, USA for their active contribution in the final agreement of these recommendations. The financial support for the International Workshop on Human Papillomaviruses and Consensus Recommendations for Cervical Cancer Prevention has been provided by the Croatian Ministry of Science, Sports and Education and the Croatian Ministry of Health and Social Welfare and several commercial companies (GlaxoSmithKline, Merck Sharp \& Dohme, Roche Diagnostics, Digene/Phoenix Pharmacija, Olympus, and Hilus). This report has been prepared with financial support of the
European Commission through the European Cancer Network and the European Network for Information on Cancer (IARC, Lyon, France) and the European Research Network of Excellence CCPRB (Cancer Control using Population Registries and Biobanking, Lund University, Malmö University Hospital, Malmö, Sweden funded by the 6th Framework programme, and by the DWTC/SSTC, Federal Service for Scientific, Cultural and Technical Affairs, Brussels, Belgium). The views expressed in the report are those of the authors; the European Commission is not responsible for any use which may be made of the information contained therein.

\section{REFERENCES}

1. Bosch FX, Lorincz A, Muñoz N, Meijer CJ, Shah KV. The causal relation between human papillomavirus and cervical cancer. J Clin Pathol. 2002 Apr;55(4):244-65.

2. Arbyn M, Primic-Zakelj M, Raifu AO, Grce M, Paraskevaidis E, Diakomanolis E, et al. The burden of cervical cancer in south-east Europe at the beginning of the 21st century. Coll Antropol. 2007 Apr;31 Suppl 2:7-10.

3. Ferlay J, Bray F, Pisani P, Parkin DM. GLOBOCAN 2002: cancer incidence. Mortality and prevalence worldwide. IARC cancer base no. 5, version 2.0. Lyon: IARC Press; 2004.

4. Znaor A, Strnad M. Cervical cancer in Croatia: state of the art and possibilities for prevention. Coll Antropol. 2007 Apr;31 Suppl 2:37-40.

5. Croatian National Institute of Public Health. Cancer incidence in Croatia. Bulletins Croatian National Institute of Public Health Zagreb. 1983-2006;no.1-29.

6. IARC Working Group on the Evaluation of Cancer-Preventive Strategies. Cervix cancer screening. IARC handbooks of cancer prevention, vol.10. Lyon: IARC Press; 2005.

7. Arbyn M, Raifu AO, Autier P, Ferlay J. Burden of cervical cancer in Europe: estimates for 2004. Ann Oncol. 2007 Oct;18(10):1708-15.

8. Pajtler M, Audy-Jurković S, Kardum-Skelin I, Mahovlić V, Vrdoljak Mozetič D, Ovanin-Rakić A. Organisation of cervical cytology screening in Croatia: past, present and future. Coll Antropol. 2007 Apr;31 Suppl 2:47-54.

9. Council of the European Union. Council recommendation of 2 december on cancer screening. Off J Eur Union. 2003;878:34-8.

10. European Commission. European Guidelines for Quality Assurance in Cervical Cancer Screening - Second Edition. Arbyn M, Anttila A, Jordan J, Ronco G, Schenck U, Segnan N, Wiener HG, Herbert A, Daniel J, von Karsa L (eds). Luxembourg: Office of Official Publications of the European Communities, 2008; pp. 1-291.

11. Grce M, Grahovac B, Rukavina T, Vrdoljak Mozetič D, Glavaš Obrovac L, Kaliterna V, et al. HPV testing for cervical cancer screening in Croatia. Coll Antropol. 2007 Apr;31 Suppl 2:67-71.

12. Kaić B, Gjenero-Margan I, Brzović M, Lakošeljac D, Aleraj B, NemethBlažić T, et al. Vaccine regulations in Croatia. Coll Antropol. 2007 Apr;31 Suppl 2:117-20.

13. Arbyn M, Dillner J. Review of current knowledge on HPV vaccination: an appendix to the European Guidelines for Quality Assurance in Cervical Cancer Screening. J Clin Virol. 2007 Mar;38(3):189-97.

14. Dillner J, Arbyn M, Dillner L. Translational mini-review series on vaccines: Monitoring of human papillomavirus vaccination. Clin Exp Immunol. 2007 May;148(2):199-207.

Accepted December 6, 2007 